http://dx.doi.org/10.5050/KSNVE.2012.22.2.193

$$
\begin{gathered}
\text { 소음지도 제작시 차량 분류방법이 소음도 예측 결과에 } \\
\text { 미치는 영향 연구 }
\end{gathered}
$$

\title{
Effects of Vehicle Classification Methods on Noise Prediction Results of Road Traffic Noise Map
}

\author{
김 지 윤*.박 인 선**. 정 우 홍***. 강 대 준****.박 상 규† \\ Ji Yoon Kim, In Sun Park, Woo Hong Jung, Dae Joon Kang and Sang Kyu Park \\ (2012년 1월 6일 접수 ; 2012년 2월 1일 심사완료)
} Key Words : Road Traffic Noise Map(도로교통 소음지도), Noise Prediction(소음예측), Vehicle Classification(차량
분류)

\begin{abstract}
Road traffic noise map is effective method to save cost and time for environmental noise assessment. Generally, noise is calculated by using theoretical equation of noise prediction, and the calculated result can be influenced by various input factors. Especially, domestic vehicle classification method for traffic flow and heavy vehicle percentage is different from that of foreign countries. Thus, this can cause effect on the noise prediction results. In this study, noise prediction results by using domestic vehicle classification method are compared with those by foreign methods.
\end{abstract}

\section{1. 서 론}

소음지도는 이론적으로 증명된 예측식 또는 실험 결과를 바탕으로 하는 실험식을 이용하여 특정 소 음원의 소음도를 예측한 결과와 지리정보를 함께 분석하여 대상지역의 소음도를 공간적으로 분석한 지도이다 ${ }^{(1)}$.

이러한 소음지도는 소음예측을 위해서 소음예측 식의 인자에 대한 정확한 정보가 필요하나, 모든 자 료를 실측하는 것은 현실적으로 불가능하므로 담당 기관의 조사 결과 또는 장기간의 통계자료를 사용 하는 것이 효율적이다 ${ }^{(2)}$. 그러나 국내의 교통량 분

† 교신저자; 정회원, 연세대학교 환경공학부

E-mail : tankpark@yonsei.ac.kr

Tel : (033)760-2442, Fax : (033)763-2194

* 정회원, (주)평화엔지니어링

** 정회원, (주)현대건설

*** 정회원, (주)제일엔지니어링

****정회원, 국립환경과학원
류기준이 해외 상용 소음지도에서 사용하는 차량분 류방법과 상이한 실정이며, 이는 소음예측식의 대형 차량비율 산정시 오차의 원인이 되어 소음예측 결 과에 영향을 줄 수도 있다. 따라서 차량 분류방법이 상이한 국내의 기준을 기존의 소음예측식에 적용하 기 위해서는 그 적합성을 평가해야 한다.

이 연구에서는 소음지도 제작시 주요인자인 차량 분류방법에 대하여 소음예측식별 차이를 비교하여, 그 적합성을 판단할 수 있는 기본자료를 제공하고자 한다.

\section{2. 이 론}

\section{1 도로교통량 조사}

도로교통량이란 '도로의 한 지점, 또는 단면을 단 위 시간 동안 통과하는 차량의 수'를 의미하며, 도 로 교통량 조사는 도로를 이용하는 각종 통행 차량 의 통과 대수를 종류별, 방향별 및 시간대별로 조사 
하는 것을 의미한다. 도로교통량 조사는 기본 교통 량 자료가 필요하다고 판단되는 모든 구간에 대하여 광범위하게 실시하는 조사인 수시조사(coverage survey)와 특정 지점에 교통량 조사 장비(고정식 조 사 장비) 를 설치하여 1 년 이상의 장기간 동안 통과 하는 차량 수를 측정하는 상시조사(continuous or permanent survey)로 구분된다 ${ }^{(3)}$. 국내의 교통량 분 류기준은 건설교통부의『교통조사지침』 ${ }^{(4)}$ 과 『도로 교통량 조사지침』이 있으며, 각각 10 종 및 11 종으 로 구분한다(Table 1). 현재 건설교통부에서는 『도로 교통량조사지침』에 따라 고속국도, 일반국도, 지방 도, 국가지원지방도에 대한 교통량 정보를 분석하여 이를『교통통계연보』및 교통량 정보 제공시스템 (http://www.road.re.kr)를 통해 제공하고 있다.

\section{2 소음예 측식별 차량분류 기준}

이 연구에서는 주요 소음예측식 중 가장 많은 국가 에서 사용하고 있는 영국의 CRTN 과 독일의 RLS90, 그리고 EU Directive5)에서 기준으로 제시한 프랑스 의 XPS 31-133 에 대하여 연구하였다.

\section{(1) $\operatorname{CRTN}(\mathrm{UK})^{(6)}$}

1975년 영국에서 도로교통소음 예측식으로 발표된 $\mathrm{CRTN}$ 의 경우, 기본소음도는 도로 가장자리에서 $10 \mathrm{~m}$ 의 거리에서 교통량, 차량속력, 차량구성, 도로기울기,

Table 1 Vehicle classification of the Korean government

\begin{tabular}{|c|c|c|c|}
\hline Types & $\begin{array}{l}\text { Directive } 1 \\
(10 \text { class })\end{array}$ & Types & $\begin{array}{l}\text { Directive } 2 \\
(11 \text { class })\end{array}$ \\
\hline Sedan & $\begin{array}{c}\text { Under } 7 \\
\text { passengers }\end{array}$ & Sedan & $\begin{array}{l}\text { Sedan, microbus } \\
\text { below } 15 \text { passengers }\end{array}$ \\
\hline Microbus & $\begin{array}{c}8 \sim 15 \\
\text { passengers }\end{array}$ & $\begin{array}{l}\text { Medium } \\
\text { bus }\end{array}$ & $15 \sim 25$ passengers \\
\hline Taxi & $\operatorname{taxi}$ & Heavy bus & Over 25 passengers \\
\hline Two axles & Two axles & $\begin{array}{l}\text { Light } \\
\text { truck A }\end{array}$ & $\begin{array}{l}2 \text { axles, } 4 \sim 6 \text { tires, } \\
\text { Below } 2.5 \text { tons }\end{array}$ \\
\hline Medium bus & $\begin{array}{c}16 \sim 35 \\
\text { passengers }\end{array}$ & $\begin{array}{l}\text { Light } \\
\text { truck B }\end{array}$ & $\begin{array}{c}2 \text { axles, } 6 \text { tires, } \\
3.5 \sim 8 \text { tons }\end{array}$ \\
\hline Heavy bus & $\begin{array}{l}\text { Over } 35 \\
\text { passengers }\end{array}$ & $\begin{array}{l}\text { Medium } \\
\text { truck C }\end{array}$ & $\begin{array}{l}3 \text { axles, } 10 \text { tires, } \\
\text { Under } 15 \text { tons }\end{array}$ \\
\hline Light truck & $\begin{array}{l}\text { Below } 2.5 \\
\text { tons }\end{array}$ & $\begin{array}{l}\text { Medium } \\
\text { truck D }\end{array}$ & $\begin{array}{l}3 \text { axles, } 10 \text { tires, } \\
\text { container }\end{array}$ \\
\hline $\begin{array}{l}\text { Medium } \\
\text { truck }\end{array}$ & $2.5 \sim 8.5$ tons & $\begin{array}{l}\text { Medium } \\
\text { truck E }\end{array}$ & $\begin{array}{c}4 \text { axles, } 12 \text { tires, } \\
\text { container }\end{array}$ \\
\hline Heavy truck & Over 8.5 tons & $\begin{array}{l}\text { Heavy } \\
\text { truck F }\end{array}$ & $\begin{array}{l}4 \text { axles, } 14 \text { tires, } \\
\text { trailer }\end{array}$ \\
\hline \multirow{2}{*}{ Trailer } & \multirow{2}{*}{ Trailer } & $\begin{array}{l}\text { Heavy } \\
\text { truck G }\end{array}$ & $\begin{array}{c}5 \text { axles, } 18 \text { tires, } \\
\text { trailer }\end{array}$ \\
\hline & & $\begin{array}{l}\text { Heavy } \\
\text { truck H }\end{array}$ & $\begin{array}{c}6 \text { axles, } 22 \text { tires, } \\
\text { trailer }\end{array}$ \\
\hline
\end{tabular}

도로포장상태 등을 고려하여 계산된다. 교통량 보정 은 양방향의 교통량을 합한 값으로 계산하는데 1.5 톤 이상의 차량을 대형차량으로 분류하며, 그 비율 은 아래의 관계식에 의해 인자 $p$ 를 결정하고 Fig. 1 을 이용하여 소음도를 보정하게 된다.

$$
p=\frac{100 f}{q} \text { or } \frac{100 F}{Q}
$$

\section{$f, F: 1$ 시간, 18 시간동안의 대형교통량}

$q, Q: 1$ 시간, 18 시간동안의 전체교통량

\section{(2) RLS90(Germany)}

독일에서 발표된 RLS90의 경우 2.8 톤 초과차량 을 대형차량으로 분류하며, 다음과 같이 소음도를 결정한다.

$$
\begin{aligned}
& \mathrm{L}_{\mathrm{m}}(25, \text { basic }) \\
& \quad=37.3+10 \log (\mathrm{M} \times(1+0.082 \times \mathrm{P}))
\end{aligned}
$$

$\mathrm{Lm}(25, \mathrm{basic})$ : 직선형 아스팔트 도로에서 일정속도의 소형차 $(100 \mathrm{~km} / \mathrm{h})$ 및 대형차 $(80 \mathrm{~km} / \mathrm{h})$ 소음도

$\mathrm{M}$ : 평균교통량(veh/h) 또는 일평균교통량(ADT)

$\mathrm{P}: 2.8$ 톤 초과차량 비율

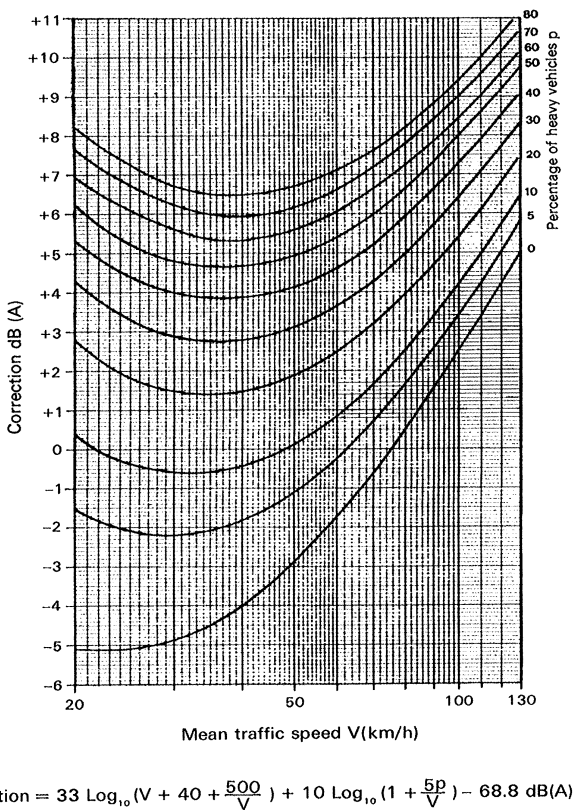

Fig. 2 Correction for mean traffic speed $V$ and percentage heavy vehicles $p^{(6)}$ 
(3) XPS 31-133(舊 NMPB, France)

프랑스에서발표된 XPS 31-133의 경우 3.5톤 이 상을 대형차량으로 분류하며, 소음방출량 상수를 적 용하여 소음도를 보정한다.

\section{3. 연구방법}

이 연구에서 소음예측을 위한 $\mathrm{S} / \mathrm{W}$ 는 상용소프트 웨어인 SoundPLAN(ver. 6.4, SoundPLAN 社)을 사 용하였다.

\section{1 대상지역 선정}

도로교통 소음예측식 비교를 위한 대상지역은 EU Directive에서 제시하고 있는 인구 및 교통량 기준에 따라, 주변에 주거지역과 상업지역이 위치하 여 평일 교통량이 비교적 일정한 원주시 개운동, 단 구동, 관설동 일대를 선정하였다. 대상도로는 교통 량이 700 대/h 이상인 도로를 선택하였다. Fig. 2는 이 지역중에서 대표적인 지역을 나타낸다.

\section{2 기초조사}

(1) 교통량

교통량 조사는 캠코더(DCR SR-80, SONY 社) 를 이용하여 1 시간 동안의 교통량을 녹화한 후, 건설교 통부 교통량 분류기준을 참고하여 분류하였다. 각 예측식별 차량분류는 Table 2 와 같으며, 차량분류결 과는 Table 3 과 같다.

(2) 속도

속도조사는 대상지역의 도로를 소구간으로 세분화

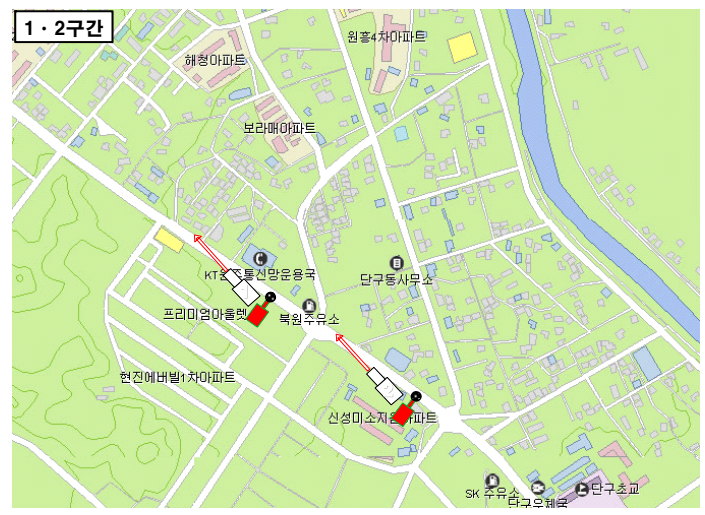

Fig. 2 Measurement area
하여 구간별 시작지점과 종료지점을 통과하는 차량 을 임의 지정하여 구간 통과시간을 측정하였으며, 이를 평균하여 구간 평균속도를 계산하였다(7). RLS90과 XPS 31-133의 경우 예측식의 특성상 소 형차량과 대형차량의 평균속도를 구분하여 적용하 였다.

(3) 기타

지형정보는 국토지리정보원에서 제공하는 디지털 수치지도(축척 1:5,000)를 이용하였으며, 건물의 높 이와 기타 도로 폭, 노면경사, 노면 포장상태 등의 정보를 조사하여 모든 예측식에 동일하게 적용하였 다. 계산된 소음도 검증을 위하여 지면과 건물에 15 지점의 소음측정 지점을 선정하고, 1 시간동안의 소 음도를 측정하였다.

Table 2 Classification of vehicle types

\begin{tabular}{c|c|c|c|c}
\hline \hline \multirow{2}{*}{ Types } & \multirow{2}{*}{$\begin{array}{c}\text { Directive } 2 \\
\text { (11 class })\end{array}$} & \multicolumn{3}{|c}{ Prediction methods } \\
\cline { 2 - 2 } & CRTN & RLS90 & XPS \\
\hline Sedan & $\begin{array}{c}\text { Sedan, microbus } \\
\text { below 15 passengers }\end{array}$ & Light & Light & \\
\hline $\begin{array}{c}\text { Light } \\
\text { truck }\end{array}$ & Below 2.5 tons & & \multirow{2}{*}{ Light } \\
\cline { 1 - 2 } $\begin{array}{c}\text { Medium } \\
\text { truck }\end{array}$ & $2.5 \sim 3.5$ tons & & & \\
\hline $\begin{array}{c}\text { Medium } \\
\text { bus }\end{array}$ & Below 25 passengers & Heavy & Heavy & \\
\hline $\begin{array}{c}\text { Heavy } \\
\text { truck }\end{array}$ & Over 3.5 tons & & & Heavy \\
\hline $\begin{array}{c}\text { Heavy } \\
\text { bus }\end{array}$ & Over 25 passengers & & & \\
\hline
\end{tabular}

Table 3 Road traffic flow for 3 prediction methods

\begin{tabular}{c|c|c|c|c}
\hline \hline \multicolumn{2}{c|}{ Traffic flow } & CRTN & RLS90 & XPS31-133 \\
\hline \multirow{2}{*}{ Section 1 } & Light & 1,537 & 1,728 & 1,761 \\
\cline { 2 - 5 } & Heavy & 271 & 80 & 47 \\
\hline \multirow{2}{*}{ Section 2 } & Light & 1,132 & 1,322 & 1.356 \\
\cline { 2 - 5 } & Heavy & 248 & 58 & 24 \\
\hline \multirow{2}{*}{ Section 3 } & Light & 873 & 1,000 & 1,010 \\
\cline { 2 - 5 } & Heavy & 215 & 88 & 78 \\
\hline \multirow{2}{*}{ Section 4 } & Light & 608 & 740 & 760 \\
\cline { 2 - 5 } & Heavy & 231 & 99 & 79 \\
\hline \multirow{2}{*}{ Section 5 } & Light & 769 & 864 & 881 \\
\cline { 2 - 5 } & Heavy & 145 & 51 & 33 \\
\hline \multirow{2}{*}{ Section 6 } & Light & 1,106 & 1,223 & 1,242 \\
\cline { 2 - 5 } & Heavy & 178 & 61 & 42 \\
\hline
\end{tabular}


Table 4 Vehicle speed (unit : $\mathrm{km} / \mathrm{h}$ )

\begin{tabular}{|c|c|c|c|c|}
\hline \multicolumn{2}{|c|}{$\begin{array}{c}\text { Section \& } \\
\text { vehicle type }\end{array}$} & CRTN & RLS90 & XPS31-133 \\
\hline \multirow{2}{*}{ Section 1} & Light & \multirow{2}{*}{62.3} & 63.9 & 62.9 \\
\hline & Heavy & & 58.8 & 59.5 \\
\hline \multirow{2}{*}{ Section 2} & Light & \multirow{2}{*}{34.1} & 34.5 & 34.6 \\
\hline & Heavy & & 33.8 & 33.5 \\
\hline \multirow{2}{*}{ Section 3} & Light & \multirow{2}{*}{53.6} & 55.8 & 53.8 \\
\hline & Heavy & & 49.6 & 52.1 \\
\hline \multirow{2}{*}{ Section 4} & Light & \multirow{2}{*}{58.5} & 59.6 & 58.7 \\
\hline & Heavy & & 55.0 & 57.0 \\
\hline \multirow{2}{*}{ Section 5} & Light & \multirow{2}{*}{46.2} & 45.6 & 45.7 \\
\hline & Heavy & & 49.5 & 58.0 \\
\hline \multirow{2}{*}{ Section 6} & Light & \multirow{2}{*}{57.4} & 65.7 & 65.7 \\
\hline & Heavy & & 38.1 & 38.1 \\
\hline
\end{tabular}

Table 5 Comparison of predicted and measured noise level (unit : $\mathrm{dB}(\mathrm{A})$ )

\begin{tabular}{|c|c|c|c|c|c|c|c|c|}
\hline \multirow{2}{*}{\multicolumn{2}{|c|}{$\begin{array}{l}\text { Measurement } \\
\text { positions \& } \\
\text { sections }\end{array}$}} & \multirow{2}{*}{$\begin{array}{l}\text { Mea- } \\
\text { sured } \\
\text { result }\end{array}$} & \multicolumn{2}{|c|}{ CRTN } & \multicolumn{2}{|c|}{ RLS90 } & \multicolumn{2}{|c|}{ XPS } \\
\hline & & & Result & Error & Result & Error & Result & Error \\
\hline \multirow{11}{*}{$\begin{array}{c}\mathrm{G} \\
\mathrm{r} \\
\mathrm{o} \\
\mathrm{u} \\
\mathrm{n} \\
\mathrm{d}\end{array}$} & $1-1$ & 74.4 & 72.6 & -1.8 & 73.1 & -1.3 & 72.8 & -1.6 \\
\hline & $1-2$ & 72.5 & 69.9 & -2.6 & 70.5 & -2.0 & 70.3 & -2.2 \\
\hline & $2-1$ & 71.6 & 70.8 & -0.8 & 68.8 & -2.8 & 71.2 & -0.4 \\
\hline & $3-1$ & 70.6 & 70.1 & -0.5 & 71.7 & +1.1 & 71.5 & +0.9 \\
\hline & $3-2$ & 69.7 & 66.7 & -3.0 & 68.8 & -0.9 & 68.8 & -0.9 \\
\hline & $4-1$ & 72.4 & 71.9 & -0.5 & 72.0 & -0.4 & 71.1 & -1.3 \\
\hline & $4-2$ & 71.8 & 70.4 & -1.4 & 70.5 & -1.3 & 69.7 & -2.1 \\
\hline & $5-1$ & 69.5 & 69.9 & +0.4 & 70.1 & +0.6 & 69.3 & -0.2 \\
\hline & $5-2$ & 68.1 & 66.4 & -1.7 & 68.2 & +0.1 & 67.6 & -0.5 \\
\hline & $6-1$ & 73.6 & 74.1 & +0.5 & 75.1 & +1.5 & 76.1 & +2.5 \\
\hline & $6-2$ & 69.5 & 67.9 & -1.6 & 70.5 & +1.0 & 72.3 & +2.8 \\
\hline \multirow{4}{*}{$\begin{array}{l}\mathrm{B} \\
\mathrm{u} \\
\mathrm{i} \\
\mathrm{l} \\
\mathrm{d} \\
\mathrm{i} \\
\mathrm{n} \\
\mathrm{g}\end{array}$} & 1 & 69.7 & 68.6 & -1.1 & 67.2 & -2.5 & 67.1 & -2.6 \\
\hline & 2 & 65.0 & 67.0 & +2.0 & 65.9 & +0.9 & 68.1 & +3.1 \\
\hline & 4 & 67.6 & 68.6 & +1.0 & 69.4 & +1.8 & 67.9 & +0.3 \\
\hline & 5 & 67.2 & 67.8 & +0.6 & 68.1 & +0.9 & 67.0 & -0.2 \\
\hline \multirow{3}{*}{$\begin{array}{l}\mathrm{A} \\
\mathrm{V} \\
\mathrm{e} \\
\mathrm{r} \\
\mathrm{a} \\
\mathrm{g} \\
\mathrm{e}\end{array}$} & $\begin{array}{c}\text { Error on } \\
\text { the ground }\end{array}$ & & & 1.3 & & 1.2 & & 1.4 \\
\hline & $\begin{array}{l}\text { Error } \\
\text { on the } \\
\text { building }\end{array}$ & & & 1.2 & & 1.5 & & 1.6 \\
\hline & Average & & & 1.3 & & 1.3 & & 1.4 \\
\hline
\end{tabular}

\section{4. 연구결과 및 분석}

CRTN, RLS90과 XPS 31-133의 예측소음도와 실 측소음도를 비교한 결과는 Table 5 및 Fig. 3 과 같 으며 대상 지역의 2-D 및 3-D 소음지도는 Fig. 4에

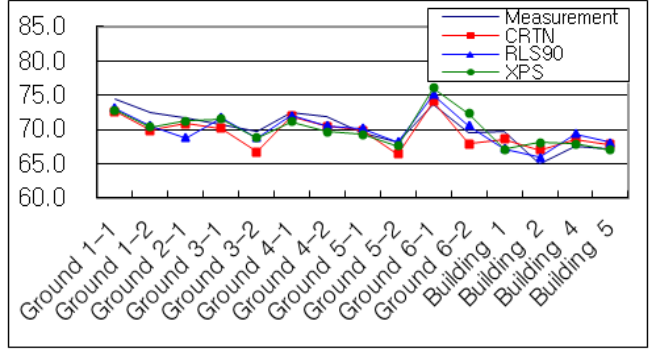

Fig. 3 Comparison of predicted and measured noise level

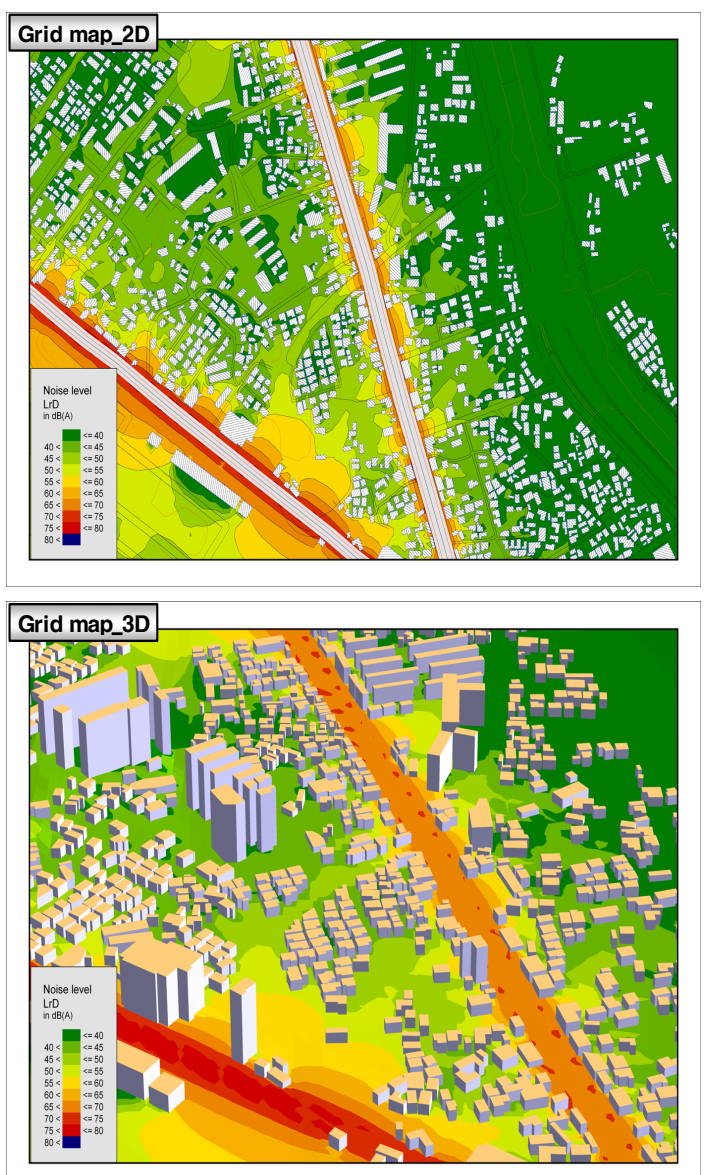

Fig. 4 Road traffic noise map of an area in Wonju city

나타내었다. 비교결과 $\mathrm{CRTN}$ 의 지면 오차범위는 $0.4 \sim 3.0 \mathrm{~dB}$, 건물 오차범위는 $0.6 \sim 2.0 \mathrm{~dB}$, 전체 오 차평균은 $1.3 \mathrm{~dB}$ 였다. RLS90의 지면 오차범위는 $0.5 \sim 2.8 \mathrm{~dB}$, 건물 오차범위는 $0.9 \sim 2.5 \mathrm{~dB}$ 였으며, 전 체 오차평균은 $1.3 \mathrm{~dB}$ 였다. XPS 31-133의 지면 오 
차범위는 $0.2 \sim 3.5 \mathrm{~dB}$, 건물 오차범위는 $0.2 \sim 3.1 \mathrm{~dB}$ 였으며, 전체 오차평균은 $1.5 \mathrm{~dB}$ 였다.

모든 예측식의 평균 오차범위는 $2 \mathrm{~dB}$ 이내의 결 과를 보였으며, 이는 인간의 청력을 통해 소음의 크 기를 감지할 수 있는 최소범위인 $3 \mathrm{~dB}$ 이내의 결과 로서 인지범위 내에서 실측소음도와 유사한 경향을 나타낸다고 할 수 있다.

\section{5. 결 론}

이 연구에서 소음지도 제작 시 주요인자인 차량 분류방법에 대하여, 세 가지 소음예측식의 예측소음 도 결과를 실측소음도를 비교하였다. 소음도 예측 결과 각 예측식의 오차범위는 CRTN $0.4 \sim 3.0 \mathrm{~dB}$, RLS90 $0.5 \sim 2.8 \mathrm{~dB}$, XPS 31-133은 $0.2 \sim 3.5 \mathrm{~dB}$ 였으 며, 오차평균은 $\mathrm{CRTN} 1.3 \mathrm{~dB}$, RLS90 $1.3 \mathrm{~dB}$, XPS 31-133 $1.4 \mathrm{~dB}$ 였다.

각 예측식별 차량분류기준과 국내의 차량분류기 준의 차이는 있으나 실측소음도와 세 가지 예측소 음도의 비교 결과, 인간의 소음 차이 인지 범위인 3 $\mathrm{dB}$ 이내이므로 세 가지 예측식 모두 적용이 가능할 것으로 사료된다.

\section{후 기}

이 연구는 2008년 연세대학교 학술연구비 및 환 경부 산하 국립환경과학원의 연구용역사업 “소음지 도 작성을 위한 연구(II)"에서 수행된 결과이며 지
원에 감사드립니다.

\section{참 고 문 헌}

(1) Park, I. S. and Park, S. K., 2003, A Study on the Development of Noise Map for Quiet Environment of Urban Areas, Proceedings of the KSNVE Annual Spring Conference, pp. 1182 1186.

(2) WG-AEN, 2006, Good Practice Guide for Strategic Noise Mapping and the Production of Associated Data on Noise Exposure, EU Commission.

(3) Ministry of Construction and Transpotation, 2001, Road Traffic Survey Guide, Government Document Registration No. 11-1500000-00608-14.

(4) Ministry of Construction and Transpotation, 2006, Traffic Survey Guide, Directive No. 2006-415.

(5) The European Parliament and of the Council, 2002, Relating to the Assessment and Management of Environmental Noise Directive 2002/49/EC, Official Journal of European Communities.

(6) Department of Transport Welsh Office HMSO, 1988, Calculation of Road Traffic, HMSO Books.

(7) Park, I. S. and Park, S. K., 2007, Effects of Measurement Method for Vehicle Speed on the Prediction Results of Noise Map, Transactions of the Korean Society for Noise and Vibration Engineering, Vol. 17, No. 2, pp. 155 159. 